\title{
The working practices and job satisfaction of dental therapists: findings of a national survey
}

\author{
D. E. Gibbons, ${ }^{1}$ M. Corrigan, ${ }^{2}$ and J. T. Newton, ${ }^{3}$
}

Objective To describe the working practices and level of job satisfaction of dental therapists in the United Kingdom.

Design Postal questionnaire survey of 380 dental therapists registered with the General Dental Council.

Results Only $13 \%$ of dental therapists are also qualified as dental hygienists. Around 75\% of those registered with the GDC are currently employed as dental therapists. Of those not currently working as dental therapists most were either working as hygienists or caring for their children at home. Over $90 \%$ of those working as therapists are employed within the Community Dental Service. About half work part-time. Part-time working is more common among respondents with childcare responsibilities. Most dental therapists are employed in clinical roles, and perform a limited range of treatments. A small proportion appear to have been asked to undertake duties which are not currently legal for them to perform. Three-quarters of those who were currently working as dental therapists had taken career breaks at some point, the most common reasons for such a break being a change in career and/or child rearing. The respondents expressed a high level of job satisfaction, particularly among older dental therapists.

Conclusions Dental therapy offers a potentially rewarding career in terms of job satisfaction. Any planned increase in the numbers of training places for dental therapists should their role be expanded, for example to include working in general dental practice, would need to take cognisance of the high rate of parttime working and the proportion who could be expected to take career breaks at some point in their working lives, as is the case with female dental practitioners.

$\mathrm{T}$ he current and potential future role of dental therapists has become a topic of great interest following the report of the Dental Auxiliary Review Group ${ }^{1}$ and the subsequent publication of a consultation document concerning professionals complementary to dentistry by the General Dental Council. ${ }^{2}$ At the present time dental therapists are only permitted to practice in the Community or Hospital Dental Services, a situation which has appertained since the inauguration of the pilot scheme for training of dental auxiliaries (as they were then known) in 1960. For many years the only available training programme for dental ther-

${ }_{1}^{1}$ Professor and Head of Department, ${ }^{2}$ Research Assistant, ${ }^{3}$ Lecturer in Psychology in Relation to Dentistry, Department of Dental Public Health \& Oral Health Services Research, Guy's, King's and St Thomas' Dental Institute, King's College London, Floor 18, Guy's Tower, Guy's Hospital, London SE1 9RT

Correspondence to: Dr J. T. Newton

REFEREED PAPER

Received 03.02.00; Accepted 11.05.00

(C) British Dental Journal 2000; 189: 435-438 apists was a 2-year course organised by the New Cross School for Dental Auxiliaries. This school closed in 1983 and was succeeded by a course at the London Hospital which took eight students who qualified as both dental hygienists and dental therapists. More recently further schools have opened at the Sheffield, Cardiff, Liverpool and Eastman Dental Schools. The numbers of dental therapists registered with the General Dental Council has always been low, varying from 268 in 1969/70 to a peak of 553 in 1982 to the current figure of $380 .^{3}$

The potential role of dental therapists in the provision of oral health services in the United Kingdom has received some attention. ${ }^{4,5}$ However there have been few empirical studies of their actual role, though the valuable role therapists within the Community Dental Service can play in clinical and epidemiological work has been discussed. ${ }^{6-9}$

The present study seeks to describe the current working practices and job satisfaction of dental therapists in the United Kingdom. Despite a large body of literature on the working practices of dental practitioners in both the United Kingdom and elsewhere (see Newton, Thorogood \& Gibbons ${ }^{10}$ for a summary) there has only been one previous study of this type for dental therapists. In 1989, the British Association of Dental Therapists undertook a national survey of dental therapists and district dental officers covering employment, pay, further qualifications, training and recruitment. An abstract of the findings of the survey was published, ${ }^{11}$ but the complete results are not available in the literature.

\section{Method}

A questionnaire survey of all 380 dental therapists registered with the General Dental Council register was carried out. All those individuals registered as dental therapists with the GDC are women. All questionnaires were anonymous.

\section{Questionnaire}

The questionnaire developed for this study was based upon the adaptation of a questionnaire used in a previous survey of dental therapists, ${ }^{11}$ and on a questionnaire used in a recent survey of the career development of dental practitioners. ${ }^{10}$ The questionnaire was pilot tested on a sample of dental therapists, following which minor modifications were made to improve wording and clarity. The questionnaire included sections covering the following areas:

- Demographic characteristics of respondent.

- Current working practice (including place of employment and duties)

- Career breaks (including number of breaks, duration and reason for taking break)

- Continuing education

- Job satisfaction 


\section{Procedure}

A copy of the research questionnaire was sent to each participant, together with a cover letter explaining the purpose of the research and a reply paid envelope. Follow-up mailings were planned should the response rate achieved in the initial posting fall below 60 per cent.

\section{Results}

Characteristics of the respondents

Replies were received from 304 dental therapists (response rate $80 \%)$. The average age of the therapists was 44.6 years $(\mathrm{SD}=8.2)$. Just under half of the respondents indicated that they had childcare responsibilities (129 individuals, 43\%). A small proportion of the sample (45 respondents, 13\%) had qualified as a dental hygienist at the same time as they qualified as a therapist. Additional qualifications had been gained by 198 respondents (65\%) since their qualification as a dental therapist, the most common being the Certificate in Dental Health Education (25\% of those who had gained an additional qualification), the Further Adult Education Teaching Certificate $(22 \%)$, the Health Education Certificate $(15 \%)$ and various qualifications in counselling $(22 \%)$.

The average number of years since qualification was 23.3 years $(\mathrm{SD}=9.5)$. A total of $227(75 \%)$ were currently working as therapists. Those not currently working as therapists were asked to describe their current occupation. Among those not working as therapists most were currently employed as dental hygienists (46 people, $60 \%$ of those not currently employed as therapists). The average number of years between qualification and ceasing to work as a therapist was 10.6 years (median $7.5, \mathrm{SD}=8.7$ ). Aside from working as a hygienist, the most commonly expressed alternative to working as a dental therapist was child rearing (19 respondents, $25 \%$ of those not currently employed as therapists).

Information on the geographic location of qualified dental therapists is not routinely collected, however the year in which individuals first register is collected. Around $12 \%$ of respondents had qualified after 1990, in comparison the proportion of therapists who first registered with the General Dental Council after 1990 is $25.7 \%$. This would suggest that the sample under-represents the most recently qualified therapists, unless incentives for registration were introduced in 1990 resulting in a large number of therapists registering at that time.

All descriptions of findings from this point forward are concerned only with those respondents who are currently practising as dental therapists $(n=227)$.

\section{Current working practice}

As might be expected, the majority of those working as dental therapists were employed in the community dental service (205 individuals, 93\%). Only 7 (3\%) respondents worked in schools of dental therapy, and $22(10 \%)$ were employed in the Hospital Dental Service (respondents could indicate that they worked in more than one service, hence percentages total more than 100). Working in more than one trust was uncommon (only 15 respondents worked in more than one trust, $7 \%$ ).

Respondents were asked to indicate in broad terms the nature of their duties in their current employment. Figure 1 shows the main areas of responsibility identified (respondents could indicate more than one area of responsibility). A large proportion of respondents identified that they had clinical responsibilities, and just over half identified a role as a dental health educator. Other roles including practice management and research were much less commonly identified.

Part-time working was defined as fewer than 30 hours per week. Just over half the respondents worked part-time by this definition (115 individuals, 53\%). Part-time working was more common

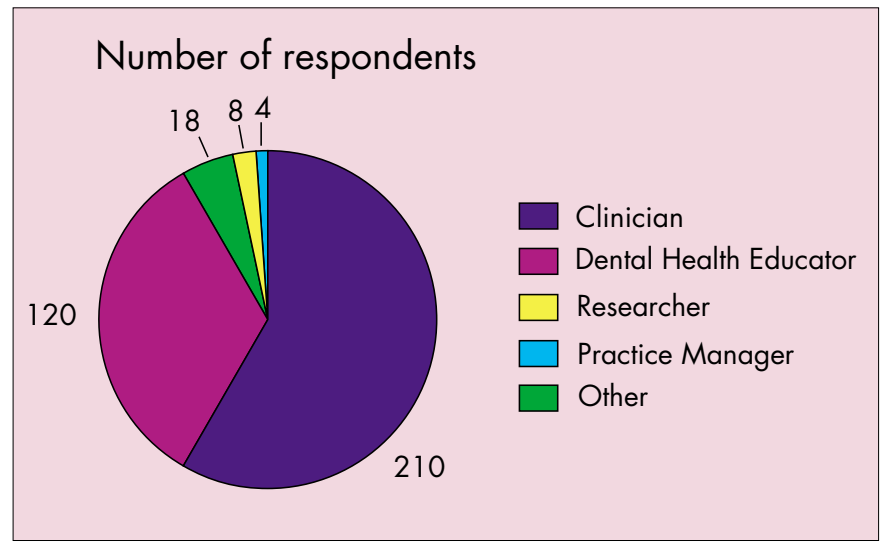

Fig. 1 Broad areas of work responsibility identified by dental therapists ( $N=227$ ) (NB respondents could report more than one area of work responsibility, therefore numbers do not total 227)

Table 1 Working hours of participants grouped according to childcare responsibilities (Data on either childcare responsibilities or working hours were not available for ten of the respondents)

\begin{tabular}{lcc}
\hline $\begin{array}{l}\text { No. of hours } \\
\text { worked in } \\
\text { last week }\end{array}$ & $\begin{array}{c}\text { Dental therapists with } \\
\text { childcare responsibilities } \\
(N=93)\end{array}$ & $\begin{array}{c}\text { Dental therapists without } \\
\text { childcare responsibilities } \\
(N=124)\end{array}$ \\
\hline $\begin{array}{l}\text { Fewer than } 30 \\
31 \text { or more }\end{array}$ & 64 & 51 \\
\hline
\end{tabular}

Chi-squared $=15.26(P<0.001)$

among those with childcare responsibilities (chi-squared $=15.26$; see Table 1).

For those dental therapists who were treating patients, almost all had the assistance of a dental nurse for most or all of their patients (207 respondents, 98\% of those who treated patients). Only one respondent had no assistance whatsoever from a dental nurse when treating patients.

Respondents were asked to indicate from a list the specific duties which they had been asked to undertake, or regularly undertake in the course of their work. This list included both duties which are currently legal for dental therapists to perform and those which are not currently permitted. The number and proportion of respondents who indicated performing each specific task is shown in Table 2.

Career breaks

Respondents were asked to indicate whether they had taken breaks in their career since qualifying as a dental therapist. A career break was defined as any period of time which they had taken away from work which lasted longer than 1 month. Figure 2 shows the number of career breaks taken by dental therapists. Seventy-five per cent of the sample had taken at least one career break. The average total length of career break of those who had taken one or more career break was 35 months ( $\mathrm{SD}=49$ months), though these data were highly skewed, the median value being 11.5 months.

The most common reason for a career break was to take up another career with all the participants who had taken a career break identifying this as a reason. The second most common reason for a career break was child rearing with 134 responses (78\% of those who had taken a break). It is possible that respondents considered that taking a break for child rearing also constituted 'taking up another career' which would go some way to explaining the high frequency of career breaks for this reason. Figure 3 shows the reasons given by people for their taking a career break. 
Table 2 Duties performed by dental therapists in their working practice. Identifying duties which respondents had been asked to undertake and those which are routinely undertaken

$$
\begin{array}{cc}
\begin{array}{c}
\text { Regularly undertake } \\
N(\%)
\end{array} & \text { Have ever undertaken but } \\
\text { do not regularly undertake } & N(\%)
\end{array}
$$

\section{Fissure sealants}

Simple fillings

Fluoride application

Dental health education

Polishing amalgams

Taking radiographs

Suture/pack removal ${ }^{*}$

Curretage*

Placing or removing

orthodontic wires/bands *

Taking impressions*

LA - ID block*

Complex fillings*

CPITN

Any other periodontal index

Dietary counselling

Pulpotomy*

Temporary dressing

Examination*

Emergency treatment without dentist's prescription *

$\begin{array}{rr}201 & (94 \%) \\ 202 & (95 \%) \\ 168 & (83 \%) \\ 190 & (93 \%) \\ 139 & (61 \%) \\ 132 & (58 \%) \\ 9 & (4 \%) \\ 11 & (5 \%) \\ & \\ 3 & (1 \%) \\ 10 & (5 \%) \\ 36 & (16 \%) \\ 88 & (39 \%) \\ 43 & (19 \%) \\ 44 & (19 \%) \\ 192 & (85 \%) \\ 23 & (10 \%) \\ 181 & (80 \%) \\ 17 & (7 \%) \\ 17 & (7 \%) \\ 17\end{array}$

$12(6 \%)$

$10 \quad 15 \%$

$30 \quad(15 \%)$

$16 \quad(7 \%)$

$42(19 \%)$

$42(19 \%$

$27 \quad(12 \%)$

$7(3 \%)$

$15(7 \%)$

$30 \quad(13 \%)$

$21 \quad(9 \%)$

$34 \quad 115 \%$

$15(7 \%)$

$16 \quad 17 \%$

$8 \quad(4 \%)$

$58 \quad(26 \%)$

$18 \quad(8 \%)$

$46(20 \%)$

$50(22 \%)$

*Indicates duties which are currently illegal for dental therapists to undertake

\section{Continuing education}

The British Dental Journal was the most popular professional journal among dental therapists with 141 people $(62 \%)$ having read it in the last 3 months. Table 3 shows the total number of respondents who reported reading various professional journals.

Most respondents (77\%) had attended a training course of at least 1 day's duration in the last year. Of those who had been on a training course 97 (43\% of respondents currently working as a dental therapist) spent between 2 and 4 days on training courses in the previous year. The most common type of course attended by dental therapists took the form of a scientific meeting (118 people, 52\%). Table 4 shows a breakdown of the time spent at training days and the type of course attended.

Job satisfaction

Respondents were asked to rate their satisfaction with their work life on a 10-point scale. The scale consisted of the numbers 1 to 10 with written anchors at each end, where $1=$ minimum satisfaction and $10=$ maximum satisfaction. Levels of job satisfaction were high, 128 respondents $(58 \%)$ rated their job satisfaction at a score of 8 or

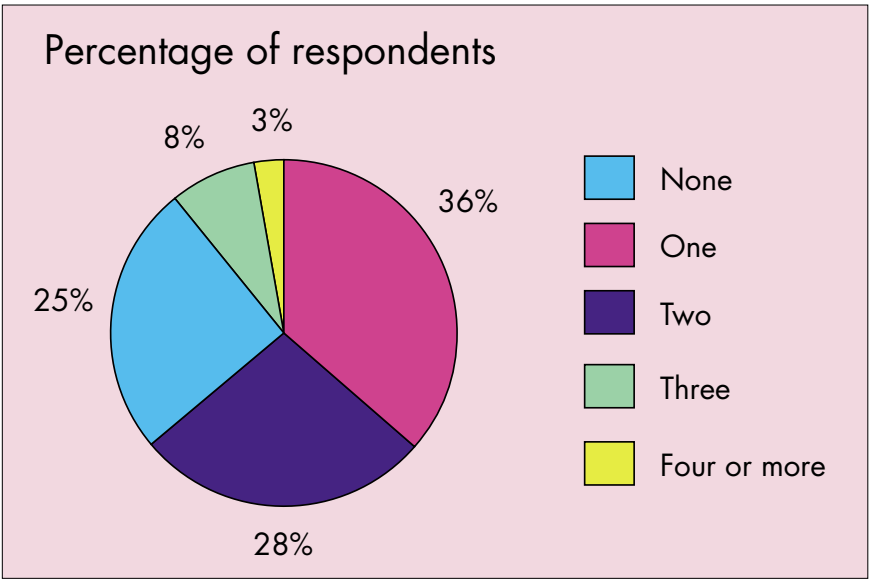

Fig. 2 Number of career breaks taken by dental therapists. Table shows percentage of respondents who took a given number of career breaks $(\boldsymbol{N}=\mathbf{2 2 7})$

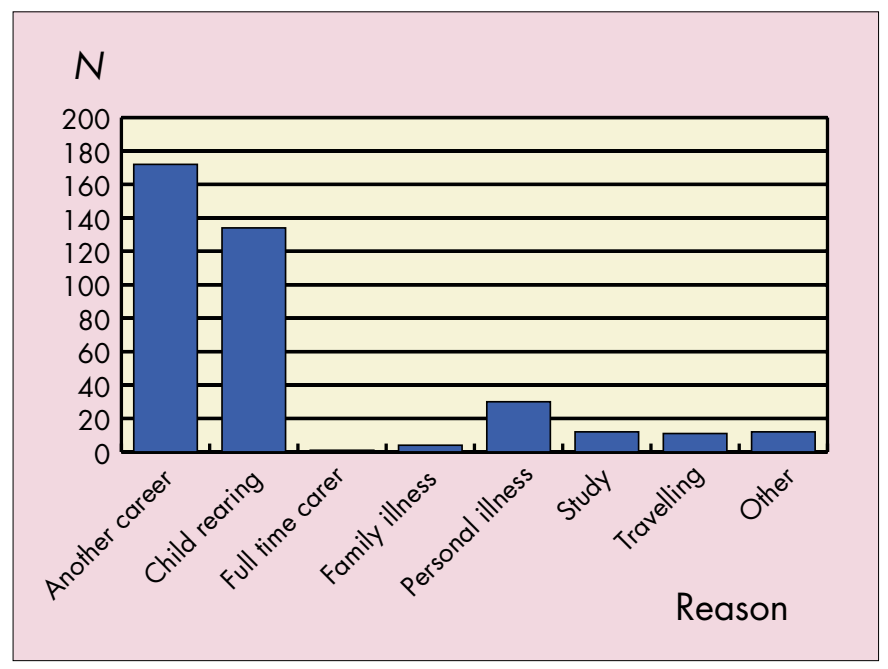

Fig. 3 Number of dental therapists who took a career break according to the reason cited for the career break $(N=227)$

\begin{tabular}{|c|c|}
\hline Journal & Number of respondents (\%) \\
\hline $\begin{array}{l}\text { The British Dental Journal } \\
\text { Dental Practice } \\
\text { Dental Health } \\
\text { The Probe } \\
\text { Dental Update } \\
\text { The Dentist } \\
\text { The Hygienist } \\
\text { Other }\end{array}$ & $\begin{aligned} 141 & (62 \%) \\
101 & (44 \%) \\
86 & (37 \%) \\
67 & (30 \%) \\
116 & (51 \%) \\
46 & (20 \%) \\
40 & (16 \%) \\
32 & (14 \%)\end{aligned}$ \\
\hline
\end{tabular}
(NB Respondents could report taking more than one career break, therefore percentages do not total 100)

*Included various newsletters but no answer with a frequency greater than three respondents

more. The mean value of job satisfaction was $7.34(\mathrm{SD}=1.94)$, the median value was 8 . Levels of job satisfaction were compared using the Mann-Whitney $U$ test for the following groups: dental therapists with and without childcare responsibilities; dental therapists above and below the median age of the sample; part-time versus full-time dental therapists. The only significant difference identified was for age - dental therapists above the median age of the sample (44 years) were on average more satisfied with their work life (median value of job satisfaction for therapists aged 45 and over $=8$; therapists aged 44 and under, median $=7$; Mann-Whitney $U=$ $4,571, P<0.05)$.

\section{Discussion}

This study reports the findings of a survey of the working practices and job satisfaction of all dental therapists registered with the General Dental Council at the 1 January 1998. It is the first study of this type to be published. A high response rate was achieved from a single mailing. The response rate from the initial posting was judged to be sufficient to ensure the representativeness of the sample. There was some suggestion that the sample may not represent those dental therapists who qualified most recently.

Few dental therapists are also qualified as dental hygienists. Those who are not currently practising as a therapist are either taking a career break for child rearing or are working as a dental hygienist. The majority of respondents who were currently working as dental 


\section{Table 4 Attendance at training courses and type of course} attended within the previous 12 months

Number of days spent in attending training courses in the previous year

Number of respondents $(\%)$

\begin{tabular}{lr} 
None & $51(23 \%)$ \\
1 day & $24(10 \%)$ \\
2 to 4 days & $97(43 \%)$ \\
5 to 10 days & $47(20 \%)$ \\
11 or more days & $8(4 \%)$ \\
\hline Type of course attended $^{\dagger}$ & \\
\hline & \\
Further dental education course & $71(31 \%)$ \\
Refresher course & $48(21 \%)$ \\
Scientific meeting $_{\text {Other }^{*}}$ & $118(52 \%)$ \\
\hline
\end{tabular}

*Included are a variety of courses, none achieving a frequency of more than three respondents aside from CPR training with six respondents, $3 \%$

tRespondents could report attending more than one type of meeting

therapists were employed in the Community Dental Service, and about half worked part-time. They expressed high levels of job satisfaction, particularly the older respondents. Most are involved in clinical work, and a small but significant proportion have undertaken duties which are not currently legal for them to perform.

The levels of job satisfaction expressed by the dental therapists in this survey are comparable to those reported for dental hygienists - a profession which also contains a high proportion of women. Studies in both the United Kingdom and the United States suggest that from 70 to 90 per cent of dental hygienists are satisfied with their career. ${ }^{12-14}$ It is interesting to note, however, that despite expressing high levels of job satisfaction two-thirds of dental hygienists would not choose it as a career if given the choice again. ${ }^{12}$ The career and job satisfaction of female dental practitioners has generally been found to be lower than that expressed here by dental therapists. ${ }^{15}$

These findings have implications for the planning of a future role for dental therapists. As a group, the dental therapists surveyed expressed high levels of job satisfaction, a large proportion read professional journals and attend continuing education. A number have taken further qualifications. Together these results suggest a highly motivated workforce who enjoy their chosen career. Expanding the role of dental therapists would necessitate an increase in the number of training places available and a consequent increase in the number of registered therapists. In planning training places due consideration should be given to the fact that many therapists work part-time and a large proportion take career breaks at some point in their life. This situation is not dissimilar from that described for female dental practitioners, ${ }^{10}$ and may not simply be the result of the individual's choice of working pattern. Availability of positions may also impact on the working patterns of therapists.

The role of sample selection should be considered in interpreting the findings reported here. The response rate was high, particularly given that only one mailing was sent out and no reminders. However there were still a proportion (20\%) of non-responders and it is possible that this may have introduced bias. It seems likely that nonresponders are less likely to be currently employed as therapists, and to be less satisfied with that role. All the respondents who had taken a career break reported taking up another career, it is possible that some therapists who do this do not return to dental therapy and fail to register with the GDC. Those dental therapists who remain on the GDC register are likely to be those who are most satisfied with their role.

\section{Conclusions}

Dental therapists in the United Kingdom are most commonly employed in the Community Dental Service where they perform clinical duties including a limited range of treatments as well as providing oral health education. A small proportion appear regularly to undertake duties which are currently illegal for them to perform. Approximately half of the respondents worked part-time and about three-quarters had taken a career break at some point in their lives. The median length of such breaks was 11.5 months. The dental therapists surveyed expressed a high degree of job satisfaction. Planning of the provision of training for future dental therapists, should their role be expanded, needs to take into account the likely preferred working patterns and conditions of service of dental therapists, in particular the likelihood that many will prefer part-time employment.

1 Dental Auxiliary Review Group. Report of the Dental Auxiliaries Review Group. London: BDA/JM Consultancy Ltd, 1998.

2 General Dental Council. Professionals complementary to dentistry. London: GDC, 1998.

3 General Dental Council. The rolls of dental auxiliaries. London: GDC, 1999.

4 Woolgrave J, Boyles J. Operating auxiliaries in the UK: A review. Community Dent Health 1984; 1: 93-99.

5 Balutis L, Morgan M. The changing role of dental auxiliaries: A literature review. Aust Dent J 1998; 43: 354-358.

6 Sutclife P. Dental auxiliaries: A method for measuring their clinical usefulness. Br Dent J 1969; 126: 418-420.

7 Jones D E, Gibbons D E, Doughty J F The worth of a therapist. Br Dent J 1981; 151:127-128.

8 Kwan S Y, Prendergast M J. The use of clinical auxiliaries as examiners in caries prevalence surveys in the UK: A feasibility study. Community Dent Oral Epidemiol 1998; 26: 194-200.

9 Kwan S Y, Prendergast M J, Williams S A. The diagnostic reliability of clinical dental auxiliaries in caries prevalence surveys: A pilot study. Community Dent Health 1998; 13: 145-149.

10 Newton J T, Thorogood N, Gibbons D E. A study of the career development of male and female dental practitioners. Br Dent J 2000; 188: 90-94.

11 Anonymous. Dental therapy and the future. Dent Practice 1991; 29:33.

12 BDHA National Survey of Dental Hygienists in the United Kingdom. London: BDHA, 1989.

13 Hillam D G. Career patterns of dental hygienists qualifying from the Liverpool Dental Hospital School of Dental Hygiene. Br Dent J 1989; 166: 310-311.

14 Boyer E M. Dental hygiene job and career satisfaction. Dent Hygiene 1988; April: 170-175.

15 Cooper C L, Watts J, Kelly M. Job satisfaction, mental health and job stressors among general dental practitioners in the UK. Br Dent J 1987; 24: 77-88. 